\title{
The Development of Bodily - Kinesthetic Intelligence through Creative Dance for Preschool Students
}

\author{
Eleni Michelaki
}

PhD student at the University of Athens, Department of Physical Education and Sport Science Basileos Georgiou B 36, Kamatero, Zip Code 13451, Athens

Email address: elenimihel@gmail.com

Pagona Bournelli

Assistant Professor at the University of Athens, Department of Physical Education and Sport Science

\author{
Doi:10.5901/jesr.2016.v6n3p23
}

\section{Abstract}

\begin{abstract}
Creative dance can confer important benefits on students of preschool age. The aim of this research was the implementation of a creative dance unit for preschoolers (five-year-olds) and the examination of its impact on the development of their bodily kinesthetic intelligence. Because of the lack of previously established tests of bodily - kinesthetic intelligence, the goal of the present study is to offer new information about the evaluation of bodily - kinesthetic intelligence for students of pre-school age. Observation was made across three creative dance sessions in order to document any progress particularly in the expression and development of their bodily - kinesthetic intelligence. Data collection methods used within the study were: observation in classes, video recordings, photography and diary. By these means we arrived at the conclusion that these creative dance sessions gave pre-school children the opportunity to employ and develop their bodily - kinesthetic intelligence.
\end{abstract}

Keywords: bodily - kinesthetic intelligence, creative dance, preschool children

\section{Introduction}

The development of modern theories, such as Gardner's theory of multiple types of intelligence, indicates the need for changes in education. These theories could be applied to creative dance by emphasizing the importance of bodily kinesthetic intelligence in the school syllabus. In addition, the ways in which different types of intelligence are involved in each creative dance unit could be more clearly understood and evaluated.

Every type of intelligence described in Gardner's theory can be actively employed and promoted in creative dance sessions. According to research carried out on children in the first class of Junior School, creative dance first and foremost activates bodily - kinesthetic intelligence with musical, verbal, spatial, interpersonal and intrapersonal intelligence coming second (Keun \& Hunt, 2006). Gardner (1983, p. 302) maintains that: of all the various uses the human body is put to, none has reached greater heights than that of dance and that none has achieved greater worldwide diversity. It seems that dance has certain characteristics relevant to the investigation of bodily - kinesthetic abilities. Educationally, dance can offer a unique body of knowledge and practice, relating to bodily - kinesthetic intelligence, which dancers have an excellent ability to employ (Blumenfeld, 2009, p. 61).

Bodily - kinesthetic intelligence is defined as the ability of the individual to use his body to solve problems, express ideas and emotions and manipulate objects. According to this definition, one basic characteristic of this type of intelligence is the ability to employ the body in different activities requiring skill to achieve one's goals. A second characteristic of bodily - kinesthetic intelligence is the development of skill in the manipulation of objects (Gardner, 1983). It appears that there is a close relation between bodily - kinesthetic intelligence and the aims and content of creative dance. Creative dance aims at the free kinetic expression of ideas and feelings through the exploration of the body and the kinetic abilities of each child. In addition, with the use of various objects (hoops, balls, scarves, newspapers) during creative dance sessions, students are enabled to familiarize with their use and improve their manipulative abilities.

The overall goal of the study was to provide creative dance sessions suitable for preschoolers and to contribute to the effort of investigating, through them, the development of the students' bodily - kinesthetic intelligence. For this purpose several questions should be answered such as: a) can the bodily - kinesthetic intelligence of pre-school students 
be cultivated through this particular creative dance programme? b) is such a programme comprehensible to students and enforceable in schools and c) what are the emotional and participatory responses of the students to the programme? Because all this information could not be covered in a single article, the data presented in this article mainly focus on the investigation of bodily - kinesthetic intelligence through creative dance sessions for preschoolers.

Though many tools have been designed for the evaluation of different types of intelligence, very few of them have been tested for their validity (Siti Rahayah, Ida Kamalawati, Mohd Sahardi, \& Isa, 2010, p. 1895). One of the problems of the theory of multiple intelligence, is the difficulty in finding valid ways of measuring the different types of intelligence (Castejón, Pérez \& Gilar, 2010, p. 483). In short it can be said that there are four general categories according to which different types of intelligence can be evaluated: a) the tests, which are concerned mainly with measurable physical abilities such as speed, endurance and flexibility $b$ ) the checklists, which are concise evaluations of the performance and preferences of an individual in various types of intelligence, but are not usually recommended as a well-founded source of information (Shearer, 2004) c) the self-report surveys such as MIDAS, which was designed as a structured interview where respondents could describe their skills and abilities (Shearer, 2012). For pre-school children, however the questionnaire has been drawn up only for parental evaluation and d) the performance appraisals which are portfolios of work-performance samples collected in order to be evaluated by an external "specialist".

A well-known evaluation tool, on the basis of work-performance, is Project Spectrum. The basic aim of Project Spectrum is the observation of students, over a period of time, and their interaction when engaged in a variety of activities involving different types of intelligence. It is a theory-based approach to assessment and educational practice in the early childhood years with the explicit goal of identifying the distinctive strengths and interests of young children (Gardner, Feldman, Krechevsky, 1998a). Project Spectrum comprised 15 curriculum options, each of which taps into particular types of intelligence. The different areas of cognitive abilities are examined through activities and learning centers. This kind of approach embeds assessment in meaningful, real-world activities and blurs the line between curriculum and assessment. Evaluation in Project Spectrum is carried out by trained individuals who usually fill in an evaluation list, according to a rating scale, in order to describe various aspects (interest, ability, performance) of each child's interactions with a variety of activities.

In Project Spectrum, for the evaluation of the movement domain, both creative and physical abilities were included in order to create a handy tool for observing the development of bodily - kinesthetic intelligence (Gardner et al., 1998a, p. 11). Creative abilities refer mainly to dance and are examined as part of a creative movement curriculum. These abilities comprise: "sensitivity to rhythm", "body control", "expressiveness", "generation of movement ideas" and "responsiveness to music". The physical abilities (strength, flexibility, speed, balance), are examined separately in an obstacle course (Gardner et.al, 1998a; Gardner, Feldman \& Krechevsky, 1998b).

Certain studies have been carried out based on Project Spectrum for the evaluation of bodily - kinesthetic intelligence (Hassan \& Maluf, 1999; Castejón et al., 2010; Almeida, Prieto, Ferreira, Bermejo, Ferrando, \& Ferrándiz, 2010; Almeida, Ptieto, Ferreira, Bermejo, Ferrando, Ferrándiz, Bermejo \& Hernández, 2011). Most of these studies employed only the abilities involved in the creative movement curriculum in order to evaluate bodily - kinesthetic intelligence and used graded scales of observation which focused on the performance of particular activities of Project Spectrum. Even though the above studies have tested the scales they use for validity and reliability, they do not explain the process of developing them. For example, it was not clear under which criteria were the observational categories formed. Another issue was whether the researchers were suitable for conducting observations on creative movement. Moreover, in spite of the fact that the ability to manipulate objects is rated high in the definition of bodily - kinesthetic intelligence, it was not included for the assessment of bodily - kinesthetic intelligence either in Project Spectrum or in these subsequent studies, and therefore a gap has been created between the definition and evaluation of bodily kinesthetic intelligence.

The present study is also based on Project Spectrum (observational categories). The basic aim was to observe preschoolers and their interaction, over a period of time, when engaged in a variety of activities involving bodily kinesthetic intelligence. Because this study was based on the evaluation of a creative dance programme, only creative and not physical abilities were tested. Before conducting the research, the relationship between the categories (abilitiescriteria) of bodily - kinesthetic intelligence and various other sources referred to these particular abilities was investigated. According to a number of researchers, dance ability includes: control of complex movements, timing and synchronization in dance performance, learning and memory in dance perception and performance, visuomotor imagery and spatial transformation, esthetics and expression (Kaufman, 2006; Bläsing, Calvo-Merino, Cross, Jola, Honisch, \& Stephens, 2012). It also seems, that many of the abilities that are used for the evaluation of bodily - kinesthetic intelligence, present quite a few similarities to psychomotor (Gp) and kinesthetic (Gk) abilities which are included in the $\mathrm{CHC}$ model for the 
definition of human intelligence (Castejón et al., 2010; Mc Grew, 2009).

The ability "generation of movement ideas" was defined according to three criteria (items) in Project Spectrum (Gardner et.al, 1998a; Gardner et.al, 1998b): 1) the ability to invent novel movement ideas or to offer extensions of ideas, which can be expressed either verbally or kinetically 2) the immediate response to ideas and images with original movements 3 ) the ability to compose simple dances. Criterion 2 can be also examined by criterion 1 , and for that reason only criterion 1 was chosen for the purposes of this study. In addition it was considered better to exclude criterion 3 , for the reason that preschool children are more likely to present spontaneous compositions of kinetic motives rather than to compose a dance. The fifth ability, "responsiveness to music", was not included in the observation categories of this study. Gardner himself maintained that this category is a combination of rhythmic perception and kinetic expression (Gardner et al., 1998a). Consequently this category can also be examined by the categories of "sensitivity to rhythm" and "expressiveness".

The programme of creative dance implemented to meet the needs of this study included units in which objects such as scarves, hoops and balloons were used. Therefore, it was considered worthwhile to include the ability "manipulation of objects" as a way of assessing bodily - kinesthetic intelligence, in order to bridge the gap that was previously created between the definition and evaluation. The evaluation for the ability "manipulation of objects", was based on certain psychomotor abilities described in the CHC theory (McGrew, 2009). Particular skills included in these abilities are: finger dexterity (P2), manual dexterity (P1), arm-hand steadiness (P7), control precision (P8) and aiming (A1).

Based on the above, we ended up with five observational categories and their criteria (items) which are presented analytically in table 1.

Table 1. The observational categories for this study

\begin{tabular}{|c|c|c|}
\hline Abilities & Items & Examines \\
\hline \multirow{3}{*}{$\begin{array}{l}\text { 1. Body control } \\
\text { (bk1) }\end{array}$} & $\mathrm{C}_{1}:$ & The ability to identify, isolate and use different parts of the body. \\
\hline & $\mathrm{C}_{2}$ : & $\begin{array}{l}\text { The ability to plan, sequence and execute movement efficiently (an effective performance of } \\
\text { movement not just random and fragmentary but allowing the child to find balance, stay immobile, } \\
\text { etc. when required). }\end{array}$ \\
\hline & $\mathrm{C}_{3}:$ & The ability to replicate movements produced by the child itself and others. \\
\hline \multirow{2}{*}{$\begin{array}{l}\text { 2. Sensitivity to rhythm } \\
\text { (bk2) }\end{array}$} & $\mathrm{r}_{1}:$ & The ability to synchronize movements to stable or changing rhythms. \\
\hline & $r_{2}:$ & The ability to develop a personal rhythm through movement and regulate it for desired effects. \\
\hline \multirow{2}{*}{$\begin{array}{l}\text { 3. Expressiveness } \\
\text { (bk3) }\end{array}$} & $\mathrm{e}_{1}$ : & The ability to express feelings and images through movement (using body postures and gestures). \\
\hline & $\mathrm{e}_{2}$ : & The ability to express feelings and moods through movement in response to different melodies. \\
\hline $\begin{array}{l}\text { 4. Generation of } \\
\text { movement ideas } \\
\text { (bk4) }\end{array}$ & $g_{1}:$ & $\begin{array}{l}\text { The ability to invent novel movement ideas or to offer extensions of ideas, which can be expressed } \\
\text { either verbally or kinetically. }\end{array}$ \\
\hline \multirow{2}{*}{$\begin{array}{l}\text { 5. Object manipulation } \\
\text { (bk5) }\end{array}$} & $\mathrm{om}_{1}:$ & The ability to skilfully manipulate objects, using fine movements of the arms and hands. \\
\hline & $\mathrm{om}_{2}:$ & The ability to skilfully manipulate objects, using gross body movements. \\
\hline
\end{tabular}

\section{Method}

The research was carried out at a public school in Athens, Greece. A preschool class of thirteen students ( 5 boys and 8 girls) were chosen for the application of the creative dance sessions. Sessions took place twice a week and lasted forty minutes. For the accomplishment of this study special permission was given by the Ministry of Education. Also, written agreement was requested from parents for the participation of their children in the research. The researcher also guaranteed that videos would be used only for research purposes and that children names would not be published.

The creative method was employed in the teaching of the research's sessions. The creative method is based on the "divergent production style". According to this style of teaching the teacher encourages students to find a number of different solutions to a particular problem (Bournelli \& Mountakis, 2008). Children were also encouraged, when was necessary, to create similar movement patterns to those of the teacher, without verbal instruction or correction.

The effects of a teaching programme usually refer to experimental approaches. The lack of an established test for 
the evaluation of bodily - kinesthetic intelligence at preschool level, as well as Garner's recommendation (1983) that different types of intelligence should be assessed through everyday activities rather than by brief tests, led to the need for a qualitative approach to the subject. According to other researchers also, the implementation and exploration of the theory of multiple types of intelligence in the classroom, should be based on the qualitative observation and recording of children's behavior in real time (Nicolini, Alessandri \& Bilancioni, 2010).

The purpose of this study is to apply seven creative dance sessions to pre-school students and to examine their effects on the development of their bodily - kinesthetic intelligence. During this process the researcher intended to investigate and suggest new information about the evaluation of bodily - kinesthetic intelligence (activities and rating scales). The evaluation of bodily - kinesthetic intelligence was carried out through the observation, description and rating of the kinetic responses of children during three lessons $\left(1^{\text {st }}, 4^{\text {th }}\right.$ and $\left.7^{\text {th }}\right)$, of the seven applied in the study. Two physical education teachers specialized in creative dance and the theory of multiple intelligence, noted down in detail children's kinetic responses in relation to the abilities of bodily - kinesthetic intelligence, and then went on to assess them using a five-level scale (1: unable, 2: almost unable, 3: able, 4: very able and 5: perfectly able).

Before collecting the data, each of the two observers separately examined the analytic text for each of the three lessons used in the analysis, and they noted next to it the ability it represented. Not all of the lesson activities were used in the evaluation, just those which were most representative, according to the two experts, for the evaluation of bodily kinesthetic intelligence. The two observers agreed in advance not only which ability will be examined in each activity, but also which particular criteria (items) would be used for its evaluation.

Data collection methods used within the study were: observation in classes; video recordings and photography; and diary. The videotaping of creative dance lessons was one of the basic means of collecting data for the study. All seven lessons were recorded, from the beginning to the end of the dance class, in order to include all of the students. The camera used was digital, with high analysis and its position within the teaching area was carefully chosen so as to cover all of the space in which the research lessons were held. For the video observations, self-designed observational sheets were used.

In this study, only qualitative data were collected and then the data were analyzed both qualitatively (developing themes) and quantitatively (rating responses on predetermined scales) (Creswell \& Plano Clark, 2006, p. 12). This design served two investigation goals: a) to compare qualitative and statistical results in order to answer the question about the development of bodily - kinesthetic intelligence of the preschoolers and b) to identify new activities which can be used for the evaluation of bodily - kinesthetic intelligence and to determine certain indications which are related to what is important (according to the two specialists) for the assessment of these activities, that is to develop rating scales for specific activities in order to evaluate bodily - kinesthetic intelligence of preschoolers. For this purpose, "mixed methods data analyses" (Onwuegbuzie \& Teddlie, 2003) were used. Under a "methodological" definition, combining at any stage in the process of research, the study is considered mixed methods because both qualitative and quantitative data analysis is taking place (Creswell et al., 2006, p. 12). A mixed method approach, goes beyond the initial goal of triangulation (confirmation of results using different methods or data sets), to also gain a better understanding (comprehension) of results, discover new perspectives, or develop new measurement tools (Tashakkori and Teddlie 1998, p.43).

The analysis of the qualitative data took place after the completion of the research intervention and after a thorough observation by the two experts of the video recorded creative dance lessons. Each student was individually observed and assessed. The procedure was time consuming as thirteen students in three separate lessons were observed, where each lesson contained six to eight observation items. Each observer filled in 39 individual observational sheets (68 observational sheets totally) and 286 items were totally analyzed. During the analysis of the data, it was necessary to repeat the observation of some students' responses, and return to previous lessons, in order to compare the students' actions and locate any possible progress in their bodily - kinesthetic intelligence. The analysis of the video recorded lessons was continually complemented by using the data recorded on the diaries that both the researcher and the teacher (who taught the lessons) kept during the whole research.

To determine the rating scales, in order to provide new evidence for the future evaluation of bodily - kinesthetic intelligence, we entered all data from the two observers into a Microsoft Access 1 database, with each item per score as a field entry (for each item that has been graded with 1, we selected all the information that describes this grade and so on). Subsequently, a report was generated per item/score that listed the precise transcription of each observer's description of the item per score. This approach to transcription, enabled us to focus on each item as the unit of analysis and review all the data we had received for each of the 10 items. Based on this view, we undertook an item by- item review with regard to the two observers' description of the kinetic responses of the preschoolers. Miles and Huberman 
(1994) matrix display strategies, informed our analysis and offered an approach for completing a systematic, review of the data on each item. These matrices facilitated the effort to compare input from different observers. At the same time, our approach to data transcription, summary, and analysis was guided by literature. Due to the fact that no child was graded with 5 by the two observers, the description of this grade was made by the researcher during the analysis stage, and was based on the descriptions of the previous grades. The final analysis provided a concise indication for each item, of the relation between the kinetic description that defines a specific score, for the evaluation of bodily - kinesthetic intelligence of preschool children.

The quantitative data, derived from the grades given by the two observers-assessors from the observational sheets, for each of the three lessons $\left(1^{\text {st }}, 4^{\text {th }}\right.$ and $\left.7^{\text {th }}\right)$. Data were analyzed using the computer software package Statistical Package for Social Scientists (SPSS). In order to determine whether there are significant differences in the means of the total value of the students' bodily - kinesthetic intelligence, between the $1^{\text {st }}, 4^{\text {th }}$ and $7^{\text {th }}$ Lesson, the data was analyzed via repeated measures ANOVA (Multivariate Analysis of Variance with repeated measures).

Construct and context validity in this research, were mostly based in the observational frame provided by Gardner's theory on multiple types of intelligence. As it was previously mentioned, the validity was also amplified with the literature review, the cross reference of other theories regarding the definition of intelligence and the abilities that prevail in dance. The reliability was based in the assumption that two researchers can provide similar interpretations following the same research course and investigating the same categories (Burns, 2000).

\section{Results}

\subsection{Qualitative findings}

Information was gathered on whether the creative dance programme cultivates bodily - kinesthetic intelligence of preschoolers. What follows is qualitative evidence of the development of bodily - kinesthetic intelligence in each ability throughout the first, fourth and seventh lesson.

Body control. During the first lesson, regarding the ability to replicate movements, preschool children do not focus and are overenthusiastic when they hear the music. Most of them can repeat some of the movements presented by the teacher, but seem unable to repeat the movements when they have to perform on their own. Pre-schoolers are not familiar with some parts of their body, and seem to lack the ability to isolate different parts of their body. During the fourth lesson, regarding the ability to efficiently plan, sequence and execute movements, pre-schoolers were asked to present initially a closed body shape and an open one after that. Many of them were not able to stand immobile and clearly present their body shapes, except for two children who manged to do so. During the seventh lesson preschool children showed improvement regarding the knowledge of their body parts and the ability to isolate them. Specifically, more than half of the students could identify and isolate different parts of their body, when the teacher asked them to place different parts of their body inside a hoop (placed on the floor). Regarding the ability to repeat and recall movements, several students do not show significant improvement. Most of them can repeat the movements when these are presented by the teacher, but remember only a few of them when they have to execute on their own.

Sensitivity to rhythm. During the first lesson, most of the children can perform rhythmic movements in music along with the teacher, but seem unable to do so when they try it on their own. Only two of them managed to follow the rhythm on their own, at some parts of the exercise. During the fourth lesson the students were asked to coordinate their movements both with their couple and with the rhythm of the music, in order to make waves using a large scarf. Almost half of them managed to coordinate their movements with their couple and some of them could also follow the rhythm of the music. During the seventh lesson, in the exercise where the students have to walk between the hoops, slowly during the slow part of the music and quickly during the fast part of the music, almost all of the children manage to differentiate their movement according to the fast or slow tempo, but only a few of them manage to follow the rhythm of the music.

Expressiveness. During the first lesson the children are not familiar with expressing themselves when they are asked. Some of them present spontaneous expressions with their face and prefer to move mostly their hands and the head. During the fourth lesson several students find it difficult to perform soft movements following the rhythm of the music. Some of the children seem to be embarrassed and others quickly lose their concentration. At the end of the seventh lesson, the teacher asks the students to use their hoops and perform gentle or staccato movements depending on the melody they hear (two different melodies). Most of the children can differentiate their movements following the changes in the melody of music. A few of them show difficulty to present their ideas when they have to perform gentle movements. 
Generation of movement ideas. During the first exercise of the first lesson, where children have to say their name and simultaneously perform an original movement, most of the students feel embarrassed and present nothing and only a few of them present familiar ideas such as ballet movements. During the exercise where children have to think and show which body parts can open and close, most of them present only a few or no ideas at all. In the fourth lesson, during the first exercise (children say their name while performing an original movement), several of the children perform variations of movements that were presented earlier by their classmates. During the exercise where they have to think of different ways in order to keep their balloon in the air, without using their hands, most of them present only a few ideas (four ideas at the most), except for one child, who seems to be very concentrated and presents nine different ideas. In the seventh lesson, during the first exercise (children say their name while performing an original movement), most of the students are trying to make an original movement and many of them manage to present their idea within the requested frame (present one idea on the spot instead of several confused movements with locomotion). In the exercise where they have to place as many different body parts (one at a time) as they can inside the hoop (placed on the floor), most of the students present a few more different ideas (five to seven) than in the previous lessons.

Object manipulation. During in the exercise where they are asked to present open and closed body shapes, using a large scarf, most of them are not able to move comfortably with it and they do not present many ideas. During the fourth lesson and regarding fine movements, several students do not seem to have the necessary ability when using their fingers and hands. In their effort to make waves using their scarves, they choose to perform gross movements with their body (going up and down using their whole body or using mostly their elbows) and many of them lose several times control of the scarf. Regarding gross movements, several children do not present significant improvement when they are asked to hold a balloon in the air with gentle hits using their palms. They often lose control of the object, as they cannot control the force that they apply on it. During the seventh lesson children present improvement regarding object manipulation (gross movements). Most of them are concentrated and seem comfortable when performing movements with their hoops. They can replicate and use the handles given by the teacher, and their arms are stretched and steady for the biggest part of the exercise.

\subsubsection{Activities and grading scales for the evaluation of bodily - kinesthetic intelligence for preschoolers}

\section{Body control}

$c_{1}$ : the teacher asks the children to place different parts of their body inside the hoop (one part at a time), which is placed on the floor.

Indicative evaluation scale

Grades 1-2: The child is not able to recognize and isolate many parts of the body and manages to present none or just a few ideas.

Grades 3-5: The child can isolate parts of the body, shows self-confidence and presents a variety of movement responses.

c2: the teacher asks the children to make a closed body shape, remain immobile and then present an open one and remain immobile too. The exercise is repeated for a few times.

Indicative evaluation scale

Grades 1-2: The child can present none or one of the two body shapes and does not manage to remain immobile during its presentation.

Grades 3-5: The child can present a closed and then an open body shape and to remain immobile during its presentation.

c3: the children repeat movements demonstrated by the teacher (usually music accompanies the exercise), which afterwards try to make on their own.

Indicative evaluation scale

Grades 1-2: The child shows a lack of concentration, does not repeat all of the movements demonstrated by the teacher, and seems unable to recall them when it has to execute on its own.

Grades 3-5: The child is concentrated, can repeat the movements demonstrated by the teacher and recall them when it has to execute on its own.

Sensitivity to rhythm

$r_{1}$ : the children perform movements following the rhythm of the music along with the teacher which afterwards are encouraged to do on their own.

Indicative evaluation scales 
Grades 1-2: For most of the part of the music, the child does not follow the rhythm correctly and does not concentrate.

Grades 3-5: The child concentrates fully and follows the rhythm, both with his teacher and alone.

$r_{2}$ : the teacher asks the children to walk between the hoops, slowly during the slow tempo of the music, and fast during the fast tempo of the music.

Indicative evaluation scale

Grades 1-2: Little difference is made, or none at all, in the child's movement during the change between slow and fast tempo of the music.

Grades 3-5: The child moves both slowly and quickly according to the slow and fast tempo, and sometimes it manages to walk according to the rhythm of the music.

\section{Expressiveness}

$e_{1}$ : the teacher tells the children how shells open slowly and cautiously and close quickly and frightened when a shark appears (showing them a picture of a shark).

Indicative evaluation scale

Grades 1-2: The child is not expressive either with its body or its face.

Grades 3-5: The child is expressive both with its body and its face and tries a number of different ways of moving in order to express its feelings.

$e_{2}$ : the teacher asks the children to perform quick and staccato or slow and gentle movements, using their hoops, in relation to the melody of the music (two different melodies). Initially the children repeat at the same time, the movements presented by the teacher, and afterwards they are encouraged to perform on their own. The evaluation takes place when the children perform on their own.

Indicative evaluation scale

Grades 1-2: The child can not differentiate its movements according to the melody or feels comfortable when doing only staccato or gentle movements (usually staccato and quick).

Grades 3-5: The child can differentiate its movements and perform both staccato and gentle movements according to the melody, and presents some ideas, having sometimes the appropriate facial expression.

Generation of movement ideas

ke1: the teacher asks the children to move with their ball in different and original ways without using their hands or present as many different and original ways as they can in order to keep their balloon in the air without using their hands. Indicative evaluation scale

Grades 1-2: The child is not concentrated, presents no ideas, or manages to perform two to four ideas most of which are similar to those presented by other children.

Grades 3-5: The child is concentrated on itself, and manages to perform five to ten ideas, some of which have not been presented before by other children.

\section{Object manipulation}

om1: the teacher asks the children to wave large scarves like the waves of a calm sea (in pairs or teams of four).

Indicative evaluation scale

Grades 1-2: The child has quite some difficulty to hold the scarf with its fingers and frequently loses control of it, it mainly uses the whole body and arms in making the movements and its wrists remain stiff.

Grades 3-5: The child can hold the scarf well with its fingers and does not lose control of it, it shows comfort in holding the scarf either with one hand or with both, and most of the time it uses its elbows and wrists to wave the scarf.

$\mathrm{om}_{2}$ : the teacher asks the children to gently hit their balloon initially with their right palm, afterwards with their left, and finally using both palms alternately.

Indicative evaluation scale

Grades 1-2: The child very often loses control of the balloon and most of the times it does not control the force that applies on it.

Grades 3-5: The child never, or only one time, loses control of the balloon and most of the times it controls the force that applies on it.

\subsection{Quantitative results}

Every student in each lesson was graded as follows: a) in each criterion with the means of the grades given by the two observer-assessors, b) in each ability with the means of the grades of the criteria which correspond to that ability and c) 
to the total value of bodily - kinesthetic intelligence (all of the abilities together), with the sum of the grades of the ability. The Means and the Standard Deviation (SD) of bodily - kinesthetic intelligence in the five abilities, as well as the total value of bodily - kinesthetic intelligence in the $1^{\text {st }}, 4^{\text {th }}$ and $7^{\text {th }}$ Lesson are presented in table 2 .

Table 2. Means and Standard Deviations (SD) of the bodily- kinesthetic intelligence in the five abilities, as well as for the total value of bodily - kinesthetic intelligence in the $1^{\text {st }}, 4^{\text {th }}$ and $7^{\text {th }}$ lesson.

\begin{tabular}{|c|c|c|c|c|c|c|}
\hline \multirow[t]{2}{*}{ Abilities / Total } & \multicolumn{2}{|c|}{$1^{\text {st }}$ lesson } & \multicolumn{2}{|c|}{$4^{\text {th }}$ lesson } & \multicolumn{2}{|c|}{$7^{\text {th }}$ lesson } \\
\hline & Mean & SD & Mean & SD & Mean & SD \\
\hline Body control & 1.77 & .39 & 2.19 & .56 & 2.96 & .43 \\
\hline Sensitivity to rhythm & 1.77 & .56 & 2.42 & .49 & 2.92 & .49 \\
\hline Expressiveness & 2.04 & .48 & 2.23 & .48 & 2.85 & .32 \\
\hline Generation of movement ideas & 1.69 & .52 & 2.15 & .38 & 2.92 & .34 \\
\hline Object manipulation & 1.81 & .52 & 2.27 & .33 & 3.19 & .63 \\
\hline Total (Total bodily - kinesthetic intelligence sums) & 9.08 & 1.12 & 11.27 & .39 & 14.85 & 1.19 \\
\hline
\end{tabular}

In order to check the reliability between the two observers (inter-rater reliability), we calculated the correlation coefficient Pearson in the $1^{\text {st }}$ lesson, which correlates the measurement of each criterion between the two observers. Because not all of the criteria of the 1st lesson were graded, we also calculated the correlation coefficient $r$ in the 4th lesson. The results showed that: the correlation coefficient $r$ takes values from $.730^{\star \star}$ to $.921^{\star \star}$. The lower reliability between the two measurements appeared in the ability of "expressiveness $\left(r_{2}\right)$ " $\left(r=.730^{\star *}\right)$, while the highest reliability appeared in the ability "rhythmic sensitivity $\left(\mathrm{e}_{2}\right)$ " ( $\left.r=.921^{\star \star}\right)$.

In order to determine whether there are significant differences in the means of the total value of the students' bodily - kinesthetic intelligence, between the $1^{\text {st }}, 4^{\text {th }}$ and $7^{\text {th }}$ Lesson, the data was analyzed via repeated measures ANOVA (Multivariate Analysis of Variance with repeated measures). The repeated measures factor (within subjects) comprised the three Lessons (the $1^{\text {st }}, 4^{\text {th }}$ and $7^{\text {th }}$ ). These results are presented in table 3 . From table 3 , it can be concluded that the variance interpreted from the model is very high in the following abilities: "Object manipulation" (89\%), "Expressiveness" (84.2\%), and "Generation of movement ideas" (81.3\%) and quite high for the abilities: "Body control" (79.7\%) and "Sensitivity to rhythm" (78.7\%).

Table 3. F, Sig. (p) and Partial Eta Squared $\left(n^{2}\right)$

\begin{tabular}{lllc}
\hline Abilities / Total & $\mathrm{F}(2,11)$ & Sig. $(\mathrm{p})$ & Partial Eta Squared $\left(\mathrm{n}^{2}\right)$ \\
\hline Body control & 21.621 & .000 & .797 \\
Sensitivity to rhythm & 20.371 & .000 & .787 \\
Expressiveness & 29.225 & .000 & .842 \\
Generation of movement ideas & 23.857 & .000 & .813 \\
Object manipulation & 44.727 & .000 & .890 \\
Total (Total bodily - kinesthetic Intelligence sums) & 131.155 & .000 & .960 \\
\hline
\end{tabular}

For the total value of bodily - kinesthetic intelligence is: $F(2,11)=131.155, p=.000<.001, n^{2}=.960$. This result, that explains $96 \%$ of the total variation, shows that there are statistically significant differences in the means of the total value of bodily - kinesthetic intelligence. The high level of the total variation confirms that the students' bodily - kinesthetic intelligence improved significantly and that the creative dance sessions had an important impact on bodily - kinesthetic intelligence. The means of the total value of bodily - kinesthetic intelligence for the $1^{\text {st }}, 4^{\text {th }}$ and $7^{\text {th }}$ lessons are presented in figure 1. 


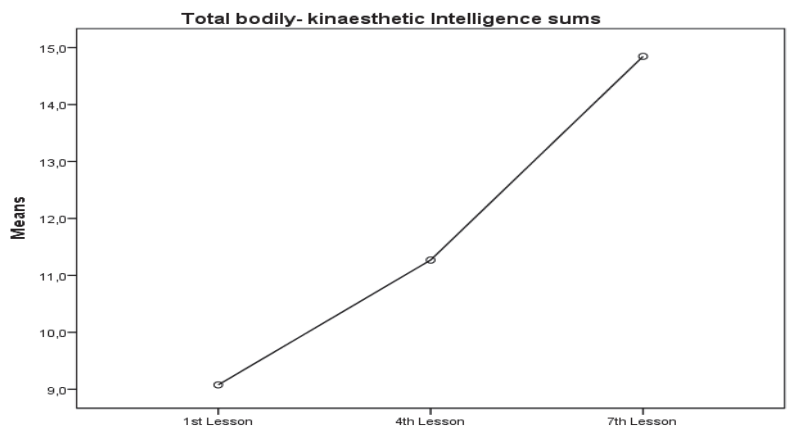

Figure 1. Means of the total value of bodily - kinesthetic intelligence for the $1^{\text {st }}, 4^{\text {th }}$ and $7^{\text {th }}$ lesson.

\section{Conclusion}

Several researchers employed Gardner's theory of multiple types of intelligence in their studies and tried to come up with reliable ways of measuring/evaluating them (Hassan \& Maluf, 1999; Castejón et al., 2010; Almeida et al., 2010; Almeida et al., 2011). From what we have observed, no research, apart from Project Spectrum, has focused in the qualitative inquiry for the definition of the activities and their scoring criteria, through which evaluation of different types of intelligence can gradually become possible.

The main goal of the current research was to compare qualitative and quantitative data in order to answer the question whether bodily - kinesthetic intelligence of preschool children can be developed through creative dance sessions. Moreover, we connected qualitative and quantitative data in order to define new activities and form indicative scales that can be used for the future evaluation of bodily - kinesthetic intelligence for preschoolers. For this purpose, mixed methods data analyses were used. The mixing of quantitative and qualitative data analysis allowed us to corroborate the various types of information and to accommodate different viewpoints about the research questions.

The qualitative results in this study were in close relation to the results from the statistical analysis which shows a good degree of agreement between the descriptive and the evaluative procedure. Analyzing the qualitative data showed that bodily - kinesthetic intelligence of preschool children can be developed through these creative dance sessions. According to these results, bodily - kinesthetic intelligence of all preschool children was improved. Some of the children presented little but satisfactory improvement and some other a significant one. The results of the statistical analysis presented that between the $1^{\text {st }}, 4^{\text {th }}$, and $7^{\text {th }}$ lesson, there was a significant difference in the Means of bodily - kinesthetic intelligence of preschool children in each ability and in the total value of bodily - kinesthetic intelligence. The high level of the total variation confirms that bodily - kinesthetic intelligence of all students has been improved through these creative dance sessions.

The scales which are presented in this study, could be a useful tool for those who wish to evaluate the bodily kinesthetic intelligence of the pre-schoolers through qualitative observation in class. Because there are no established tests of bodily - kinesthetic intelligence, similar efforts to the one we have made but on a larger scale (more lessons and a larger number of children) would strengthen research in this direction.

Creative dance can be considered as a unique body of knowledge relating to bodily - kinesthetic intelligence. Aiming at the free kinetic expression of ideas and feelings through the discovery of the body and in combination with the use of various objects in lessons, creative dance has a very close connection to bodily - kinesthetic intelligence.

The means of bodily - kinesthetic intelligence in abilities range from 1.77 ( $1^{\text {st }}$ Lesson) to 3.19 ( $7^{\text {th }}$ Lesson) (max. value 5) and in the total value of bodily - kinesthetic intelligence ranges from 9.08 (1st Lesson) to 14.85 (7th Lesson) (max. value 25). Future research, with the application of more creative dance sessions, could investigate as to whether the pre-schoolers' bodily - kinesthetic intelligence could be developed even further.

\section{References}

Almeida, L.S., Prieto, M.D., Ferreira, A.I., Bermejo, M.R., Ferrando, M., Ferrándiz, C., Rosario Bermejo, R. \& Daniel Hernández, D.

(2011). Structural invariance of multiple intelligences, based on the level of execution. Psicothema, 23(4), 832-838.

Almeida, L.S., Prieto, M.D., Ferreira, A.I., Bermejo, M.R., Ferrando, M. \& Ferrándiz, C. (2010). Intelligence assessment: Gardner 
multiple intelligence theory as an alternative. Learning and Individual Differences, 20, 225-230.

Bläsing, B., Calvo-Merino, B., Cross, E.M., Jola, C., Honisch, J. \& Stevens, C.J. (2012). Neurocognitive control in dance perception and performance. Acta Psychologica, 139, 300-308.

Blumenfeld, D. (2009). Bodily-Kinesthetic Intelligence and Dance Education: Critique, Revision, and Potentials for the Democratic Ideal. The Journal of Aesthetic Education, 43(1), 59-76.

Bournelli, P. \& Mountakis, C. (2008). The Development of Motor Creativity in Elementary School Children and Its Retention, Creativity Research Journal, 20(1), 72-80.

Burns, R. (2000). Introduction to research methods. Sage Publications: International Edition.

Castejón, J. L, Pérez, A.M \& Gilar, R. (2010). Confirmatory factor analysis of Project Spectrum activities. A second-order g factor or multiple intelligences? Intelligence, 38, 481-496.

Creswell, J. W., \& Plano Clark, V. L. (2006). Designing and Conducting Mixed Methods Research. Thousand Oaks, CA: Sage. D

Gardner, H. (1983). Frames of mind. New York: Basic Books.

Gardner, H., Feldman, D. H., Krechevsky, M. (Eds.). (1998a). Project Spectrum: Preschool Assessment Handbook. New York: Teachers College Press.

Gardner, H., Feldman, D. H., Krechevsky, M. (Eds.). (1998b). Building on Children's Strengths: The Experience of Project Spectrum. New York: Teachers College Press.

Hassan, K. \& Maluf, G. (1999). An Application of Multiple Intelligences in a Lebanese Kindergarten. Early Childhood Education Journal, $27(1), 13-20$.

Kaufmann, K.A. (2006). Inclusive creative movement and dance. Champaign: Human Kinetics.

Keun, L. L. \& Hunt, P. (2006). Creative Dance: Singapore children's creative thinking and problem-solving responses. Research in Dance Education, 7(1), 35-65.

McGrew, K. S. (2009). CHC theory and the human cognitive abilities project: standing on the shoulders of the giants of psychometric intelligence research. Intelligence, 37, 1-10.

Miles, M., \& Huberman, A. (1994). Qualitative data analysis (2nd. ed). Thousand Oaks, CA: Sage.

Nicolini, P., Alessandri, G., \& Bilancioni, G. (2010). Web-Ob for multiple intelligences observation. Procedia - Social and Behavioral Sciences, 2(2), 728-732.

Onwuegbuzie, A. J., \& Teddlie, C. (2003). A framework for analyzing data in mixed methods research. In A. Tashakkori \& C. Teddlie (Eds.), Handbook of mixed methods in social and behavioral research (pp. 351-383). Thousand Oaks, CA: Sage.

Tashakkori, A., \& Teddlie, C. (1998). Mixed methodology: Combining qualitative and quantitative approaches. Thousand Oaks: Sage Publications.

Shearer, C.B. (2012). An Inter-rater Reliability Study of a Self-assessment for the Multiple Intelligences. International Journal of Psychological Studies, 4(3), 131-138.

Shearer, C.B. (2004). Using a Multiple Intelligences Assessment to Promote Teacher Development and Student Achievement. Teachers College Record, 106(1), 147-162.

Siti Rahayah, A., Ida Kamalawati, A. B., Mohd Sahardi, C. H. \& Isa, A. (2010). Verification of multiple intelligences construct validity in an online instrument. Procedia Social and Behavioral Sciences, 9, 1894-1899. 